DOI 10.1007/s00417-003-0833-3

Paulus T. V. M. de Jong Jacobus Lubsen

\section{The standard gamble between cataract extraction and AMD \\ The standard gamble between cataract}

\author{
extraction and AMD
}

Received: 19 November 2003

Accepted: 1 December 2003

Published online: 18 December 2003

(C) Springer-Verlag 2003

P. T. V. M. de Jong

Netherlands Ophthalmic Research Institute, KNAW,

Amsterdam, The Netherlands

P. T. V. M. de Jong

Department of Ophthalmology,

Academic Medical Center,

Amsterdam, The Netherlands

P. T. V. M. de Jong · J. Lubsen

Department of Epidemiology

and Biostatistics,

Erasmus Medical Center,

Rotterdam, The Netherlands

J. Lubsen

SOCAR Research SA,

Nyon, Switzerland

P. T. V. M. de Jong (

NORI,

Meibergdreef 47, Amsterdam, 1105 BA,

The Netherlands

e-mail: p.dejong@ioi.knaw.nl

Fax: +31-20-5669050
Present-day ophthalmology in many countries is characterised by subspecialisation as some colleagues take pride in having on their cards: cataract only, glaucoma only or (medical) retina only. This may impact especially on high-throughput cataract clinics where indications may become stretched when the patient supply dwindles. One of the problems in deciding on an indication for cataract surgery is the topic of this editorial: the relation between cataract surgery and the subsequent development of age-related macular degeneration or, as we now prefer to call it, ageing macular disease

(AMD). In most cases, cataract surpervisor of residents, one of us is regularly struck by the discrepancy the eagerness of the resident to put another patient with lens opacities on the cataract roll. Taking a history of what exactly the patients' complaints and expectations are, and balancing this with the results of a careful examination, are the first steps to prevent disappointment with the outcome of surgery.

Van der Hoeve mentioned in 1918 the high prevalence of AMD in his clinic-based population ( $6 \%$ between 61-69 years and 30\% above the age of 80) and found in his AMD cases little cataract, leading to a hypothesis that cataract could protect against AMD [8]. He also mentioned a case gery is an elective procedure. As subetween the patients' complaints and of AMD after cataract extraction [8] and the dangers of UV light [9]. A relationship between cataract surgery and subsequent incident AMD

(iAMD) was reported around 1979 in six eyes that had drusen and retinal pigment epithelium (RPE) alterations that developed a haemorrhagic RPE detachment following cataract extraction $[2,6]$. In the ensuing cross-sectional NHANES-I study increasing odds ratios (ORs) for prevalent AMD (pAMD) were found with increasing lens opacities, but aphakic patients had the highest OR of 4.6 [13].

Unaware of these previous data, we decided to look into our histopathologic database of post-mortem eyes after seeing two patients who had regained full vision 1 month after uneventful extra-capsular cataract extraction with IOL implant and subsequently experienced rapid vision loss because of neovascular (nv) AMD. There was a significantly higher prevalence of nvAMD in 82 pseudophakic eyes compared to 126 phakic eyes [19]. It was difficult to get this paper accepted because the reviewers suggested that this finding was coincidental and that probably the surgeons did not look at pre-existent AMD in the fundus before cataract surgery. Next a small clinical series $(n=33)$ was reported pointing to an enhanced risk of nvAMD after cataract surgery [17]. No explanation was given for the difference in 
iAMD in first eyes (6\%) and fellow eyes $(33 \%)$ with similar techniques and experienced surgeons [17]. The on-average 1-year difference in age of the patients between these two operations did not seem to explain this [17]. Also, a large clinic-based casecontrol study in 3,688 subjects found an OR of 1.69 for lens opacities and of 1.53 for previous cataract surgery [3]. Finally, also YAG-laser capsulotomy was mentioned as a risk factor for subsequent AMD [17].

Pooled data from three population-based prevalence studies pointed at an OR of 1.7 after cataract surgery without differentiation between geographic atrophy (ga) AMD and nvAMD [5]. The presence of cataract itself also was associated with an increased OR for AMD after adjusting for age, race, sex and smoking [5]. Possibly due to the pooling of whites, blacks (lower AMD prevalence?) and Hispanics, there were only $166(1.5 \%)$ AMD cases in this study. The population-based Beaver Dam Eye Study found no association between cataract at baseline and 10year incidence of AMD, although cataract surgery before baseline was associated with a relative risk of gaAMD of 3.18 and of nvAMD of 4.31 [11]. The most recent paper pooling incident AMD data from the Beaver Dam and Blue Mountains Eye Studies showed that of 11,393 eyes at risk, $4 \%$ of operated eyes developed nvAMD over the 5-year period following cataract surgery compared with $0.4 \%$ of phakic eyes [21]. The authors found ORs of 4 for incident nvAMD and 3.1 for incident gaAMD after cataract surgery [21]. The study probably lacked the power to perform a paired-eye analysis for each case. Recently, however, also several smaller clinical series were published demonstrating the beneficial effect of cataract surgery in patients with AMD [1, 4, 14].

Where do we now stand with these partially controversial results? Although it is at present difficult to give precise numbers, one must assume that cataract surgery is associ- ated with an increased probability or risk of subsequent AMD. Hence, the patient with reduced vision to whom cataract surgery is proposed is in fact asked to choose between the continuation of a certain but imperfect health state (the current disability due to cataract) and a gamble between future AMD with probability $P$, or a perfect health state (cataract removed) with probability $1-P$. This type of choice is similar to the "standard gamble' proposition as used in clinical decision analysis and quality of life research [7]. As Kassirer has put it, it "involves the choice between possible outcomes that may be viewed differently by different patients. In such cases we should identify a patient's preferences scrupulously" [10]. How would the meticulous ophthalmologist go about this? Suppose that the patient was able to score the amount of current subjective Disability due to cataract as a number $\mathrm{D}_{\mathrm{C}}$ between $0=$ no disability at all and $1=$ totally disabled. It should be stressed that the issue here is not loss of vision measured objectively by ophthalmologic investigation, but subjective disability. For the same amount of objective loss of vision due to cataract, the amount of subjective disability may vary greatly between a painter and a jazz musician, some of whom have never learnt to read music notes anyway. Suppose also that the patient was somehow able to express his perception of the amount of subjective disability that would be associated with AMD if it occurs after cataract surgery as a number $\mathrm{D}_{\mathrm{AMD}}$ with similar properties as $\mathrm{D}_{\mathrm{C}}$. We can then individualise the decision whether or not to recommend cataract surgery as follows. No surgery means that the disability resulting from cataract $\left(D_{C}\right)$ will continue unchanged with certainty, at least in the near future. This is the simple option, as it involves no probabilistic element. The surgical option is more complex. If all goes well, vision will be restored and subjective disability will be reduced to zero. Let us keep things simple and forget about the risk of acute complications of surgery, or failure of the procedure. These risks should today be small indeed. Let us therefore only consider the risk of AMD, which we have denoted earlier by $P$, and assume that it occurs soon after surgery, if at all. (In practice AMD can also gradually occur after an initial AMD-free period. This can easily be taken into account in the argument that follows, but we shall ignore it here.) Because of the risk of AMD, the surgical option involves a probabilistic element. This element can be accounted for by considering the expected disability associated with surgery, which is equal to $P \times \mathrm{D}_{\mathrm{AMD}}+(1-P) \times \mathrm{D}_{\text {no } \mathrm{AMD}}$ (the risk of AMD times the disability associated with AMD if it occurs, plus the risk of no AMD times the disability associated with no AMD). Because we assume that vision is restored after surgery if AMD doesn't occur, the disability associated with no AMD is equal to zero. Hence, we can write the expected disability associated with surgery as $P \times \mathrm{D}_{\mathrm{AMD}}$. There is nothing that can be done about the risk of AMD (that can nowadays be quantified according to age and stage of AMD [12]) without cataract surgery. But one can recommend surgery only when the expected disability associated with surgery is less than the disability due to cataract, i.e., when $P \times \mathrm{D}_{\mathrm{AMD}}<\mathrm{D}_{\mathrm{C}}$. This can be written also as $P<\mathrm{D}_{\mathrm{C}} / \mathrm{D}_{\mathrm{AMD}}$. In two landmark papers published in 1975 [15] and 1980 [16], Pauker and Kassirer have outlined the essential elements of the "threshold approach to clinical decision making". The ratio $\mathrm{D}_{\mathrm{C}} / \mathrm{D}_{\mathrm{AMD}}$ can be considered as a threshold that determines whether the risk of AMD is worth taking when recommending cataract surgery. If the risk of AMD is below $\mathrm{D}_{\mathrm{C}} / \mathrm{D}_{\mathrm{AMD}}$, surgery is recommended. If the risk of postoperative AMD (still to be documented exactly by future studies) is above this ratio, surgery should be avoided. Note that the threshold depends entirely on the ratio of $\mathrm{D}_{\mathrm{C}}$ to $\mathrm{D}_{\mathrm{AMD}}$. If $\mathrm{D}_{\mathrm{C}}$ is bigger 
than $\mathrm{D}_{\mathrm{AMD}}$, surgery would always be recommended. This is intuitively clear as in that case the surgery simply replaces a more serious disability by a less serious one, even if AMD occurs. The decision problem occurs when $D_{C}$ is smaller than $D_{A M D}$. For instance, if $\mathrm{D}_{\mathrm{AMD}}$ is considered 100 times worse than $\mathrm{D}_{\mathrm{C}}$, even a risk of AMD of 1 in 100 is not worth taking.

We have outlined above the existence of a threshold for cataract surgery to come to conclusions about the future direction of both clinical research and practice concerning cataract surgery. The controversy about the increased risk of AMD needs to be resolved and the ophthalmologist needs to be provided with a validated method to estimate the increased risk based on relevant determinants. Most family physicians and cardiologists are familiar with charts for assessing the risk of coronary disease based on age, gender, smoking habits, cholesterol, etc. There is no reason why similar charts for the risk of AMD after cataract surgery could not be developed. In addition, methods need to be developed to obtain individualised estimates of $\mathrm{D}_{\mathrm{C}}$ and $\mathrm{D}_{\mathrm{AMD}}$ that suit the patient concerned. With these in hand, it will then be possible to tailor the decision to the patient's real needs, thereby avoiding over-utilization of cataract surgery. This will both improve the quality of care and reduce its costs.

Until these data are available it follows that the indications for cataract surgery may have to become more stringent again than is the case in some ophthalmology practices today, following safer operation techniques. Also, the benefits and risks of cataract surgery should be discussed with regard to subsequent de- velopment of AMD with each candidate for surgery. It probably also means that bilateral cataract surgery in one session, as is advocated by some due to logistic ease, should be discarded in patients with early AMD. Finally cataract surgeons should remove "only" from their cards again and look carefully with a 90-D lens at the fundus after having examined the type of cataract.

\section{References}

1. Armbrecht AM, Findlay C, Aspinall PA, Hill AR, Dhillon B (2003) Cataract surgery in patients with age-related macular degeneration: 1-year outcomes. J Cataract Refract Surg 29:686-693

2. Blair CJ, Ferguson J Jr (1979) Exacerbation of senile macular degeneration following cataract extraction. Am J Ophthalmol 87:77-83

3. Chaine G, Hullo A, Sahel J, Soubrane G, Espinasse-Berrod MA, Schutz D, Bourguignon C, Harpey C, Brault Y, Coste M, Moccatti D, Bourgeois H (1998) Case-control study of the risk factors for age-related macular degeneration. France-DMLA Study Group. Br J Ophthalmol 82:996-1002

4. Desai P, Reidy A, Minassian DC, Vafidis G, Bolger J (1996) Gains from cataract surgery: visual function and quality of life. Br J Ophthalmol 80:868-873

5. Freeman EE, Munox B, West SK, Tielsch JM, Schein OD (2003) Is There an association between cataract surgery and age-related macular degeneration? Data From three population-based studies. Am J Ophthalmol 135:849856

6. Gass JDM (1997) Stereoscopic atlas of macular diseases, 2nd edn. CV Mosby, St Louis, p 73

7. Gold MR, Siegel JE, Russell LB, Weinstein MC (1996) Cost-effectiveness in health and medicine. Oxford University Press, New York

8. Hoeve J van der (1918) Senile Maculadegeneration und senile Linsentrübung. Graefes Arch Clin Exp Ophthalmol 98:1-6

9. Hoeve J van der (1918) Schädigungen des Auges durch Licht. Senile Linsentrübungen und senile Maculadegeneration. Graefes Arch Clin Exp Ophthalmol 98:49-66

10. Kassirer JP (1994) Incorporating patient's preferences into medical decisions. N Eng J Med 330:1895-1896
11. Klein R, Klein BE, Wong TY, Tomany SC, Cruickshanks KJ (2002) The association of cataract and cataract surgery with the long-term incidence of agerelated maculopathy. Arch Ophthalmol 11:1551-1558

12. Leeuwen $\mathrm{R}$ van, Klaver CCW, Vingerling JR, Hofman A, De Jong PTVM (2003) The risk and natural course of age-related maculopathy. Follow-up at $61 / 2$ years in the Rotterdam Study. Arch Ophthalmol 121:519-526

13. Liu IY, White L, LaCroix AZ (1989) The association of age-related macular degeneration and lens opacities in the aged. Am J Public Health 79:765-769

14. Lundstrom M, Brege KG, Floren I, Lundh B, Stenevi U, Thorburn W (2002) Cataract surgery and quality of life in patients with age-related macular degeneration. Br J Ophthalmol 86:1330-1335

15. Pauker SG, Kassirer JP (1975) Therapeutic decision making: a cost-benefit analysis. New Engl J Med 293:229_ 234

16. Pauker SG, Kassirer JP (1980) The threshold approach to clinical decision making. N Eng J Med 302:1109-1117

17. Pollack A, Marcovich A, Bukelman A, Oliver M (1996) Age-related macular degeneration after extracapsular cataract extraction with intraocular lens implantation. Ophthalmology 103:15461554

18. Pollack A, Bukelman A, Zalish M, Leiba H, Oliver M (1998) The course of age-related macular degeneration following bilateral cataract surgery. Ophthalmic Surg Lasers 29:286-294

19. Schaft van der TL, Mooy CM, Bruijn de WC, Mulder PG, Pameyer JH, Jong de PTVM (1994) Increased prevalence of disciform macular degeneration after cataract extraction with implantation of an intraocular lens. Br J Ophthalmol 78:441-445

20. Shuttleworth GN, Luhishi EA, Harrad RA (1998) Do patients with age-related maculopathy and cataract benefit from cataract surgery? Br J Ophthalmol 82:611-616

21. Wang JJ, Klein R, Smith W, Klein BEK, Tomany S, Mitchell P (2003) Cataract surgery and the 5-year incidence of late-stage age-related maculopathy: pooled findings from the Beaver Dam and Blue Mountains eye studies. Ophthalmology 110:1960-1967 